\title{
MEDIDAS PARA PREVENIR LA PRODUCCIÓN DE ESCOMBROS EN ROMA Y SUS MUNICIPIOS
}

\section{MEASURES TO PREVENT THE PRODUCTION OF BUILDING RUBBLE IN ROME AND ITS MUNICIPALITIES}

\begin{abstract}
Rosario de Castro-Camero*
RESUMEN: Leyes municipales, senadoconsultos y constituciones imperiales recogían la prohibición de demolición de edificios si no se hacía con ciertas garantías. Esto demuestra la preocupación del mundo romano por la conservación del entorno urbano. En el presente artículo explicaremos qué medidas y recursos se emplearon para evitar la generación de escombros y proteger un interés distinto del individual.
\end{abstract}

Palabras clave: Escombros, prohibición de demolición, operis novi nuntiatio, leyes municipales, senadoconsultos.

ABSTRACT: Municipal statutes, Senate resolutions and imperial constitutions referred to the prohibition of building demolition without certain guarantees. This reveals the Roman concern about the preservation of the urban environment. In this article we shall explain what measures and resources were employed in order to prevent the generation of building rubble and protect an interest other than individual.

Keywords: Building rubble, demolition ban, "operis novi nuntiatio", municipal statutes, Senate resolutions.

\section{INTRODUCCIÓN ${ }^{1}$}

En el mundo antiguo, la ciudad fue un potente instrumento de romanización y un eficaz medio de propaganda del poder político, además de la forma y el símbolo a través del que se expresaba y comunicaba esa sociedad. No obstante, el fenómeno urbano siempre ha llevado aparejado algunos inconvenientes, como es el de la aglomeración de población y la consiguiente generación de residuos. Para evitar que estos provocasen daños a la salud, al medio ambiente o a la estética se articularon mecanismos con los que minimizar su impacto. En este sentido, cabe señalar que la prevención fue uno de los instrumentos más eficaces a los que se recurrió; de la misma manera que también hoy sigue siéndolo. Al evitar o reducir el volumen de los escombros se limitaba también el problema de su gestión y eliminación. A continuación, pasamos a analizar con detalle estos recursos, unos obligatorios y

\footnotetext{
* Profesora Titular de Derecho Romano (Universidad de Sevilla). Dirección postal: Calle Enramadilla 18-20, 41018 Sevilla (España). Dirección electrónica: rdcastro@us.es

1 El presente trabajo ha sido llevado a cabo en el marco del Proyecto de I+D, "Funciones y vínculos de las elites municipales de la Bética. Marco jurídico, estudio documental y recuperación contextual del patrimonio epigráfico. I" (ORDO V), Referencia: HAR2014-55857-P, del Programa Estatal de Fomento de la Investigación Científica y Técnica de Excelencia del Ministerio de Economía y Competitividad, cofinanciado por el Fondo Europeo de Desarrollo Regional.
} 
otros voluntarios, cuya existencia pone de relieve, a nuestro juicio, que aunque no podamos hablar de una Derecho del Medio Ambiente romano, sí observamos una incipiente preocupación por la conservación del entorno urbano en condiciones adecuadas ${ }^{2}$.

Dos fueron, principalmente, los tipos de medidas de prevención con las que se intentó disminuir, en Roma, la producción de escombros. Por un lado, a través de la prohibición legal de demolición de inmuebles; y, por otro, mediante un instrumento de carácter voluntario, la denuncia de obra nueva.

\section{LA PROHIBICIÓN DE DEMOLICIÓN DE EDIFICIOS EN LEYES MUNICIPALES, SENADOCONSULTOS Y CONSTITUCIONES IMPERIALES}

De forma acertada, algunos autores como A. Fernández de Buján han puesto de manifiesto el simplismo que conlleva sostener que, a lo largo de toda la historia del Derecho Romano, se mantuvo la misma concepción del derecho de propiedad predominante en época arcaica. La irrupción de la buena fe y la equidad como criterios reguladores de las relaciones jurídicas abrió paso a otra serie de consideraciones de tipo social o público que, a partir del período clásico, tuvo como consecuencia una progresiva limitación del dominio ${ }^{3}$. En este sentido, Robinson defiende que, aunque fue a partir del siglo III cuando el intervencionismo del poder público se hizo más evidente, ya desde época republicana y los primeros años del Principado, puede observarse cómo en muchas ocasiones se deja el derecho privado para hacer frente a situaciones que requerían una solución diferente. Sin embargo, a pesar de ello, era necesario que la iniciativa la tuviera siempre un ciudadano, que actuaría como parte interesada, defendiendo un interés propio o colectivo ${ }^{4}$.

2 Ruiz y Alburquerque (2011) p. 409 consideran que, aunque desde el punto de vista dogmático-técnico, no existe un Derecho Ambiental romano, sí se puede hablar de una experiencia administrativa dirigida a la protección de los recursos naturales. ZAMORA (2005) p. 675, por su parte, admite la existencia, en un plano secundario, de un régimen jurídico del medio ambiente en Roma. A través de este, se habría intentado controlar la contaminación generada por la descarga de desechos. Las medidas que integraban dicho régimen fueron, sobre todo, de tipo civil o administrativo.

3 Fernández de Buján (1999) pp. 10s. Respecto a la consideración de la propiedad durante el período arcaico, De Robertis (1972) pp. $42-45$ pone de relieve cómo las limitaciones a la misma no se dieron, entre otros motivos, porque no eran necesarias. La actividad edilicia, que hubiera podido requerirlo, era reducida y, por el contrario, la extensión del ager publicus disponible era muy amplia. A juicio de PONTE (2007) pp. 68-70, la expresión utilitas publica hacía referencia al interés del conjunto de ciudadanos (utilitas civium, hominum, omnium, communis) y también al de la cosa pública, entendida como comunidad de ciudadanos y, en último lugar, al interés del Estado como entidad autónoma. La autora constata cómo ni el edicto del pretor ni las leyes republicanas la mencionan. Tampoco los juristas clásicos la utilizan, a excepción de Papiniano, Paulo y Ulpiano. Sin embargo, durante la época postclásica, se recurre al criterio de la utilitas publica con frecuencia, tal y como puede comprobarse en un amplio número de constituciones imperiales.

4 Robinson (1996) pp. 41y ss. En el período del Principado, no habrían existido propiamente normas de derecho administrativo. Los remedios de este tipo encontraron acomodo necesariamente dentro de los límites del derecho privado; solo en el Dominado tuvo un pleno desarrollo, en detrimento del marco iusprivatístico. Sucedía,como señala la autora, algo muy parecido a lo que de hecho sucede en nuestros días. Sin embargo, LuzzatTo (1965) pp. 205y ss., 209, 243 sostiene una opinión bien distinta. En nuestra época el derecho administrativo tiende a expandir su influencia al ámbito jurídico-privado, pero en Roma fue al revés. Prueba de ello es que, en la medida en que era posible, se intentaba que las relaciones administrativas encajaran dentro de los esquemas y la terminología del derecho privado. Los interdictos, por ejemplo, se daban entre particulares para 
A mi modo de ver, el análisis de las fuentes hace que sea necesario matizar en gran medida la postura de Robinson contraria al reconocimiento de Derecho administrativo romano. En efecto, distintos testimonios, epigráficos y jurídicos nos permiten comprobar cómo el Derecho Romano protegió las condiciones en las que se desarrollaba la vida urbana ciudadana. En este sentido, Cicerón sostenía que el alma, el espíritu, la sabiduría y el pensamiento de la ciudad radicaban en sus leyes, siendo estas necesarias para poder ser los ciudadanos libres. En consecuencia, consideramos que la tutela del entorno urbano debía estar sometida al Derecho5.

La legislación de los municipios y colonias romanos contiene numerosos testimonios que demuestran cómo se protegía la convivencia ciudadana. Gracias a esto conocemos qué medidas de prevención se adoptaron en relación con la producción de escombros en las comunidades provinciales. Seguidamente pasamos a analizar los datos más importantes que al respecto nos transmiten las leyes de Tarento, Heraclea, Osuna e Irni.

La más antigua de ellas, la ley de Tarento (líns. 32-38), de época republicana, establecía que nadie podía destejar ni demoler ni arruinar un edificio, salvo cuando era para restaurarlo, a no ser que contase con la autorización del senado local ${ }^{6}$. El que lo hiciere sería multado (quanti id aedificium fuerit), siendo la mitad de la cantidad recaudada entregada al erario municipal y la otra mitad dedicada a los juegos públicos que organizase el magistrado encargado de su exacción:

Nei quis in oppido quod eius municipi e[r]it aedificium detegito neiue dem[olito] neiue disturbato, nisei quod non deterius restiturus erit, nisei d[e] s(enatus) s(ententia). Sei quis aduersus ea faxit, quant[i] id aedificum $<f>$ [u]erit, tantam pequni[a]m municipio dare damnas esto eiusque pequnie [qu] ei uolet petiti[o] esto. Magi(stratus) quei exegerit dimidium in [p] ublicum referto, dimidium in $[[u]$ deis, quos publice in eo magistrate facie[t], consumito, seiue ad monumentum suom in publico consumere uolet, l[icet]o idque ei s(ine) f(raude) s(ua) facere liceto ${ }^{7}$.

Por otra parte, la Tabula Heracleensis (II.20-56) expone con detalle la obligación de los particulares, propietarios de inmuebles situados delante de una vía pública, de cuidar el estado de conservación de la misma ${ }^{8}$. La ley no habla expresamente de prohibición de de-

\footnotetext{
defender sus intereses. Incluso aquellos que tenían legitimación activa popular no se daban por utilidad pública sino para proteger un interés privado.

5 Cic. pro Cluentio 53,146: [...] Neque me illa oratio commovet, quod ait Accius indignum esse facinus, si senator iudicio quempiam circumvenerit, legibus eum teneri: si eques Romanus hoc idem fecerit, non teneri. Ut tibi concedam hoc indignum esse, quod cuius modi sit iam videro, tu mihi concedas necesse est multo esse indignius in ea civitate quae legibus contineatur discedi ab legibus. Hoc enim vinculum est huius dignitatis qua fruimur in re publica, hoc fundamentum libertatis, hic fons aequitatis: mens et animus et consilium et sententia civitatis posita est in legibus. Ut corpora nostra sine mente, sic civitas sine lege suis partibus, ut nervis et sanguine et membris, uti non potest. Legum ministri magistratus, legum interpretes iudices, legum denique idcirco omnes servi sumus ut liberi esse possimus.

6 Sobre esta ley y su papel como precedente más cercano de la ley de Osuna, Caballosy Colubí (2006) pp. 20-27.

7 Edición de CraWford et al. (1996).

8 Rodríguez (2006) p. 398 señala cómo esta tabla recoge disposiciones dadas, en un principio, para la ciudad de Roma y que, posteriormente, se quieren aplicar al municipio heraclense. Galsterer (2006) pp. 40 y ss.
} 
De CASTRo-Camero, Rosario $\square$ Medidas para prevenir la producción de escombros...

molición de edificios, si bien nos ofrece una interesante información: el motivo por el que debían realizarse tales labores de mantenimiento. Este no era otro que permitir el uso de las vías por el populus (II. 20):

[...]Quae uiae in urbem Rom(am) propiusue u(rbem) R(omam) p(assus) m(ille) ubei continente habitabitur sunt erunt, quoius ante aedificium earum quael uiae erunt, is eam uiam arbitratu eius aed(ilis), quoi ea pars urbis h(ac) l(ege) obuenerit, tueatur; isque aed(ilis) curato uti quorum/ ante aedificium erit quamque uiam h(ac) l(ege) quemque tueri oportebit, ei omnes eam uiam arbitratu eius tueantur, neue eol loco $a<q>($ ua) consistat, quo minus conmode populus ea nia utatur. vacat ${ }^{9}$.

Así, pues, con base en esta fuente y en otras que a continuación examinaremos, podemos afirmar que, en gran parte, muchas de las medidas que se tomaron en orden a limitar la generación de escombros fueron consecuencia, a mi juicio, del interés de la comunidad por el cómodo uso de las vías y otros espacios públicos.

Las comunidades de Urso, Malaca e Irni también dispusieron de normas para controlar la proliferación de solares vacíos y ganar espacio habitable a través de la obligación de reconstrucción de inmuebles a corto plazo. A juicio de Rodríguez Neila, esto era beneficioso no solo para la estética de la ciudad (Dig. 43,8,2,17 [Ulp. 68 ed.]), sino también para la higiene pública, pues se impedía que estos solares se convirtieran en vertederos ${ }^{10}$.

La ley de la colonia Genetiva Iulia, de fundación cesariana, establecía en su capítulo 75 la misma prohibición de destejar, demoler o arruinar edificios de la colonia ${ }^{11}$, a menos que se diese garantía a los dunviros de su reconstrucción o bien un decreto decurional así lo hubiera resuelto, siempre que en la sesión estuvieran presentes más de cincuenta senadores $^{12}$. Si se contravenía la norma, se imponía una multa, aunque a diferencia de lo establecido en el municipio de Tarento, esta era por quanti ea res erit y no se destinaba la mitad de lo recaudado a juegos públicos. Por otra parte, a mi juicio, conviene señalar que el texto se habla de "reedificación", no de "restauración". Reconstruir un edificio es distinto de restaurarlo. Esto último significa reestablecer, volver a su estado anterior, en definitiva, conservar su estructura original; mientras que el término "reedificar" tiene un contenido más amplio, no limitado a la recuperación del edificio:

Ne quis in oppido coloni(ae) Iuli(ae) aedificium detegito neue demolito neue disturbato, nisi si praedes IIuir(um) arbitratu dederit se re<d>aedificaturum, aut nisi decuriones decreuerint, dum ne minus (quinquaginta) assint, cum e(a) r(es) consuelatur. Si quis aduersus ea fece<rit>, q(anti) e(a) r(es) e(rit), t(antam) p(ecuniam) c(olonis) c(oloniae) G(enetiuae)

\footnotetext{
9 Edición de CrawFord et al. (1996).

10 Cfr. Rodríguez-Neila (2011) p. 31.

11 LEWIs (1989) pp. 42-44 ha realizado una interesante comparación de la ley de Osuna con la de Tarento, algo anterior, y observa cómo en ambas se repite la fórmula detegito... demolito... disturbato.

12 A juicio de Robinson (1996) p. 43, esta fianza que se solicitaba jugaba un papel similar al que, en Roma, desarrollaba la cautio damni infecti. La autora llama también la atención sobre el hecho de que la asamblea decurional tenía poder suficiente para permitir la demolición sin exigir la reconstrucción del edificio. Asimismo, LEWIS (1989) pp. 45y ss. opina que, al requerir la ley de Osuna la prestación de una caución para realizar el derribo, se estaba aplicando la misma solución que en Roma cuando ante un eventual daño futuro se solicitaba del inmueble vecino la cautio damni infecti.
} 
Iu(liae) $d$ (are) d(amnas) e(sto), eiusq(ue) pecuniae qui uolet petitio persecutioq(ue) ex h(ac) l(ege) esto ${ }^{13}$

Me gustaría destacar que la legislación Flavia municipal (copias Malacitana e Irnitana) se expresa de modo muy similar a las otras leyes que la precedieron. En el capítulo 62 de ambas leyes, bajo la rúbrica $N e$ quis aedificia, quae restituturus non erit, destruat se dispone lo siguiente ${ }^{14}$ : que nadie desteje, destruya o se ocupe de demoler edificios situados dentro de los muros del municipio o contiguos a estos si no va a ser restaurado en el lazo de un año, a menos que el senado municipal lo hubiera autorizado estando presente en la sesión la mayoría de los decuriones ${ }^{15}$. Como en la ley de Osuna, la acción que se ejercita contra el infractor es una acción popular y la condena es también por el valor de la obra (is quanti ea res erit, tantam pecuniam... dare damnas esto):

Ne quis in oppido municipi Flavi Irnitani, quaeque ei oppido / continentia aedificia erunt, aedificium detegito destrui-/to demoliundumve curato, nisi <de> decurionum conscriptorum-lve sententia, cum maior pars eorum adfuerit, quod res-ltituturus intra proximum annum non erit. Qui adversus / ea fecerit, is quanti ea res erit t(antam) p(ecuniam) municipibus municipi Flavi / Irnitani d(are) d(amnas) esto, eiusque pecuniae deque / ea pecunia municipi eius municipi qui volet cuique per h(anc) 1(egem) li-/cebit actio petitio persecutio esto//16.

Por lo que respecta a la Urbe, la mayor parte de la doctrina considera que, dado que las leyes municipales regulaban de modo muy similar la cuestión, tuvo que haber habido también en Roma una legislación específica al respecto ${ }^{17}$. El precedente más antiguo de esta prohibición, según Robinson, se situaría en las XII Tablas $(6,8)$, que habría impedido la retirada de la viga hurtada empotrada en un edificio para evitar el derrumbamiento del mismo (Dig. 47,3,1 pr. [Ulp. 37 ed.] $)^{18}$. En cualquier caso, en el siglo I, tenemos ya dos se-

\footnotetext{
13 Edición de CRAWFord et al. (1996).

14 Este capítulo hace referencia a las obras realizadas en edificios privados. Los caps. 77 y 82 de la misma ley se dedican a las obras llevadas a cabo sobre vías, fosas o cloacas públicas. Para ellas eran competentes los dunviros y ediles, con la autorización decurional. Su actuación, por otra parte, debía hacerse sin perjudicar los intereses privados. Cfr. Dupré y Remolà (2002) p. 43 n. 9. Cfr. sobre los magistrados municipales a los que correspondía la realización de tales obras públicas, Pérez (2011) p. 221.

15 Considera Lewis (1989) pp. 45s., que el hecho de que en la ley Irnitana, años más tarde, se emplee la expresión detegito destruito demoliendum curato, sustituyéndose el sustantivo demoliendum por la forma verbal demolito, obedece al énfasis que se quiere dar al acto de demolición, que no consistiría en una mera alteración de la construcción sino en su derribo total.

16 Edición de D’Ors y D’Ors (1988).

17 De acuerdo con LEWIS (1989) pp. 41, 50, las previsiones recogidas en las leyes municipales sobre la prohibición de demolición reflejaban la práctica habitual de la capital. Por eso sostiene que, aunque en Roma no existiera en época republicana una disposición legal específica prohibiendo las demoliciones de edificios, sí hubo una regla en tal sentido, que era de general aplicación. Las peculiaridades que se aprecian, en concreto, en la ley de Osuna ponen de relieve que, a partir de la regla general, surgieron otras versiones. Fernández (1989) p. 79 sostiene que las leyes de los municipios y colonias romanos no recogían un derecho especial, propio de estas comunidades. Era el mismo derecho que se aplicaba en Roma y en otros lugares. Para ello analiza los capítulos 73 y 74 de la ley de Osuna, a propósito de la prohibición de enterramientos dentro de la ciudad, y los pone en relación con la ley de las XII Tablas 10,1 y 10,9, Dig. 47,12,3,5 (Ulp. 25 ed.) y CJ. 3,44,12.

18 Cfr. Robinson (1996) pp. 43-45. A su juicio, el procedimiento establecido para obtener un permiso de demolición debió ser muy parecido en Roma y en los municipios provinciales, al menos durante el período correspondiente al siglo I. En este sentido la autora considera que fue a través de una actio popularis la forma de hacer
} 
De CASTRo-Camero, Rosario $\square$ Medidas para prevenir la producción de escombros...

nadoconsultos, uno de época de Claudio y otro de Nerón, dedicados específicamente a esta problemática. El tenor del primero de ellos, el senadoconsulto Hosidiano del año 44 d.C., es el siguiente:

Cn. Hosidio Geta, L. Vagellio cos. X k. Octobr. SC. Cum providentia optumi principis tectis quoque urbis nostrae et totius Italiae aeternitati prospexerit, quibus ipse non solum praecepto augustissimo set etiam exsemplo suo prodesset, con veniretq(ue) felicitati saeculi instantis pro portione publicorum operum etiam privatorum custodi[a], deberentque abstinere se omnes cruentissimo genere negotiationis, ne[que] inimicissimam pace faciem inducere ruinis domum villarumque, placere: si quis negotiandi causa emisset quod aedificium, ut diruendo plus adquireret quam quanti emisset, tum duplam pecuniam, qua mercatus eam rem esset, in aerarium inferri, utiq(ue) de eo nibilo minus ad senatum referretur. Cumque aeque non oportere[t] malo exsemplo vendere quam emer [e, u]t venditores quoque coercerentur, qui scientes dolo malo [co] ntra hanc senatus voluntatem vendidissent, placere : tales venditiones inritas fieri. Ceterum testari senatum, domini[s nibil] constitui, qui rerum suarum possessores futuri aliquas [partes] earum mutaverint, dum non negotiationis causa id factum [sit]. Censuere. In senatu fuerunt CCCLXXXIII ${ }^{19}$.

El Senado disponía con esta resolución la prohibición de enajenación de edificios para su demolición con objeto de proceder posteriormente a la venta de sus elementos arquitectónicos. La sanción prevista para tal tipo de negocio, calificado de crudelísimo, era la nulidad de la transacción y la imposición, al comprador, de una multa por el doble del precio de la cosa. El vendedor, en cambio, sufría solo los efectos de la nulidad del acto, pero no era sancionado. La forma de reclamarse dicha cantidad debió de ser a través del proceso privado ordinario.

Pocos años más tarde, el senadoconsulto Volusiano, del 56 d.C., dado durante el gobierno de Nerón, vino a aclarar algunas de las disposiciones que ya antes se habían recogido en el Hosidiano:

[Q.] Volusio, P. Cornelio cos. VI non. Mart. SC. Quod Q. Volusius, P. Cornelius verba fecerunt de postulatione necessari[orum] Alliatoriae Celsil[l]ae, q(uid) d(e) e(a) (r)e f(ieri) p(laceret), d(e) (e)a (r)e (i)ta (c)ensuerunt: Cum SC., quod factum est Hosidio Geta et L. Vagellio cos., clarissimis viris, ante $d[i e m X$.] $k$. Oct. auctore divo Claudio, cautum esset, ne quis domum villamve dirueret, qu[o plus] sibi adquireret, neve quis negotiandi causa eorum quid emeret venderetve, poenaq(ue) in emptorem, qui adversus id SC. fecisset, constituta esset, [ut] qui quid emisset duplum eius quanti emisset in aerarium inferre cogere|tur et eius qui vendidisset inrita fieret venditio, de iis autem, qui reru suarum possessores futuri aliquas partes earum mutassent, dummodo non negotiationis causa mutassent, nibil esset novatum, et necessari Alliatoriae Celsil[l]ae, uxoris Atilii Luperci ornatissimi viri, exposuis|sent huic ordini, patrem eius Alliatorium Celsum emisse fundos cum aedificis in regione mutinensi, qui vocarentur campi Macri, in quibus locis mercatus a[g]i superioribus solitus esset temporibus, iam per aliquod

valer tales prohibiciones. LEWIS (1989) pp. 51-53, a propósito de la prohibición de quitar vigas empotradas en una casa vecina, sostiene que las leyes municipales lo que hicieron fue recoger, con más detalle, el principio expresado ya en las XII Tablas.

19 Edición de Riccobono (1941). 
annos desisset haberi, eaque aedificia longa vetustate dilaberentur neque refecta usui essent futura, quia neque habitaret in iis quisquam nec vellet in deserta [a]c ruentia commigrare: ne quid fraudi multae poenaeq(ue) esset Celsil[l]ae, si ea aedificia, de quibus in hoc ordine actum esset, aut demolita fuissent, aut ea condi[c]ione sive per se sive cum agris vendidisset, ut emptori sine fraude sua ea destruere tollereque liceret; in futurum autem admonendos ceteros esse, ut apstinerent se a tam foedo genere negotiation[is], hoc praecipue saeculo, quo excitari nova et ornari universa, quibus felicitas orbis terra|rum splenderet, magis conveniret, quam ruinis aedificiorum ullam partem deform [ari] Italiae et adhuc retinere priorum temporum [incuriam quae universa affecisset], ita ut diceretur senectute ac tum[ulo iam rem Romanam perire]. Censuere. In senatu [fuerunt... $]^{20}$.

Este senadoconsulto se expresa en los mismos términos que el anterior, prohibiendo la demolición del edificio y su venta con ánimo de lucro, pero no aquella que se realizara por su propietario con otra finalidad ${ }^{21}$. La nulidad del acto y la multa por el doble del precio de compra sigue siendo la sanción. Esta norma es una interpretación auténtica del senadoconsulto Volusiano, dada por el Senado ante el interés mostrado por una tal Alliatoria Celsilla, con propiedades en el norte de Italia que, una vez enviudó, probablemente consideró la posibilidad de vender los referidos inmuebles y trasladarse a Roma. Murga pone de relieve cómo tal venta, en un momento en que la agricultura y la ganadería de esa región se encontraban en decadencia, solo habría resultado conveniente si los ornamentos que enriquecían la construcción podían ser retirados ${ }^{22}$. Sin embargo, Maffi destaca una importantísima diferencia entre este senadoconsulto y el Hosidiano que tiene que ver con el hecho de que el Volusiano mencione expresamente la nulidad de las ventas de los elementos arquitectónicos del inmueble, algo que en el Hosidiano tan solo se suponía ${ }^{23}$.

A mi juicio, es fundamental tener en consideración para entender estos dos senadoconsultos, su conexión con la problemática de la especulación inmobiliaria y el mercado de materiales. El derrumbamiento de un edificio dejaba un solar disponible que normalmente traía consigo un enriquecimiento para su propietario que, dado el poco terreno disponible en Roma, podía pedir un elevado precio de compra por el suelo o por los materiales o bien solicitar el pago de una renta alta, si optaba por reedificarlo. En este sentido, Murga pone de relieve cómo las primeras líneas del senadoconsulto Hosidiano, donde se recogen las expresiones malum exsemplum y cruentissimum genus negotiationis, revelan el sentimiento de preocupación que empezó a generarse en Roma, a mediados del siglo I, por la creciente especulación inmobiliaria que estaba provocando un notable deterioro de la belleza de la

\footnotetext{
20 Edición de Riccobono (1941).

21 A juicio de Rodríguez-Neila (2011) p. 36, el sc. Hosidiano de aedificiis non diruendis prohibió la demolición de edificios con el fin de traficar con sus materiales; mientras que el sc. Volusiano estimuló la realización de obras para evitar que Italia se cubriera de ruinas.

22 Murga (1976) pp. 26-30. A este respecto es interesante cfr. Gelichi (2000) pp. 18 y ss., donde pone de relieve cómo, sobre todo partir de la segunda mitad del s. II, la Italia del norte vuelve a ser zona de frontera, lo que tuvo importantes efectos a nivel urbanístico, al quedar amplias zonas urbanas, en la región de Emilia, parcialmente abandonadas.

23 Maffi (1977) pp. 565 y ss.
} 
De CASTRo-Camero, Rosario $\square$ Medidas para prevenir la producción de escombros...

ciudad $^{24}$. Dos eran las formas de esta especulación: una, a través de la adquisición del suelo para influir en su precio y lucrarse con ello $^{25}$; y otra, la que se realizaba mediante la demolición de los edificios y la posterior venta de los materiales con los que estaban construidos. Como señala Rodríguez Neila, eran muchos los bloques de viviendas que se caracterizaban por ser construcciones altas y mal cimentadas, de manera que cualquier inundación podía dañarlas seriamente. Así, pues, era habitual que muchos edificios presentaran un estado ruinoso y que se produjera su derrumbamiento. Por otra parte, los incendios también solían afectarles con frecuencia debido a que la estrechez de las calles facilitaba su propagación ${ }^{26}$. De todas estas situaciones los especuladores se beneficiaban.

Cabe señalar, por lo demás, que tambiénen el Digesto encontramos referencias a esta regulación senatorial. En concreto, un texto de Paulo (Dig. 18,1,52 [Paul. 54 ed.]) explica cómo el senado decretó que no se demoliese ninguna casa, ya estuviera situada en la ciudad o en el campo, para obtener con ello un lucro, y que tampoco se vendiese algo de ellos con ánimo de especular (negotiandi causa). La venta, como ya sabemos, era considerada nula y la multa que se imponía era por el doble del precio de compra, que debía ser ingresada en el erario público por el comprador, quien en compensación y dada la nulidad del acto, podía reclamar al vendedor el precio pagado. Paulo comenta, además, cómo la disposición afectaba tanto a ventas de casas propias como ajenas:

Senatus censuit, ne quis domum villamve dirueret, quo plus sibi adquireretur neve quis negotiandi causa eorum quid emeret venderetve: poena in eum, qui adversus senatus consultum fecisset, constituta est, ut duplum eius quanti emisset in aerarium inferre cogeretur, in eum vero, qui vendidisset, ut irrita fieret venditio. Plane si mihi pretium solveris, cum tu duplum aerario debeas, repetes a me: quod a mea parte irrita facta est venditio. Nec solum huic senatus consulto locus erit, si quis suam villam vel domum, sed et si alienam vendiderit.

\footnotetext{
24 Murga (1976) p. 20. Por su parte, Rainer (1987) p. 31 pone de relieve cómo el Senado, en lugar de prohibir directamente la demolición, optó por limitar la libertad contractual privada al declarar ineficaz la compra de un edificio realizada por el mero ánimo de especular. En cualquier caso, señala Procchi (2001) pp. 413-415, se trataba de un caso de invalidez relativa, pues no afectaba a la eficacia traslativa del acto.

25 Garnsey (1976) pp. 124-126. Para Procchi (2001) pp. 425, 430, 437y ss., sin embargo, la finalidad de estos senadocosultos no era directamente la de impedir la especulación inmobiliaria en sí misma o el comercio de materiales de construcción sino, en concreto, un tipo de negocio que se estaba realizando con inmuebles en buen estado de habitación, que estaba creando un escenario de ruina altamente lesivo para el aspecto de la ciudad.

26 Cfr. Rodríguez-Neila (2011) pp. 28, 32, 35. Para evitar las inundaciones, gracias a Tac. ann., 1,79, sabemos que en el año 15 se emprendieron obras en el cauce del Tíber. Por otra parte, a juicio de este autor, muchos incendios fueron vistos por los especuladores como una oportunidad. Cicerón, propietario de numerosos edificios, escribió a su amigo Ático cómo esperaba obtener provecho de su proyecto de reconstrucción tras el incendio de dos de estos. Otro ejemplo lo tenemos en el incendio de Roma del año 64. Nerón, aprovechando este suceso, prometió erigir pórticos delante de los edificios a sus expensas y entregar los solares a sus dueños libres de escombros, además acometió la tarea de una nueva regulación del trazado de Roma, ordenando la alineación de las manzanas, limitando la altura de los edificios y dejando espacios abiertos (Tac., ann. 15,43,1-2). Se modificaba así la anterior división en catorce regiones realizada por Augusto. En opinión de RoBINSON (1996) p. 9, la decisión de pasar de las cuatro regiones de época republicana (Suburana, Esquilina, Colina y Palatina) a catorce fue consecuencia de la nueva división administrativa del imperio llevada a cabo también durante este período.
} 
Desde mi punto de vista, el que este fragmento siga hablando, en relación con los senadoconsultos ya mencionados, de la prohibición de derribo de casas tanto urbanas como rurales, pone de relieve que dichas normas no se dieron por una motivación estética. La demolición de una casa situada en el campo no tenía ninguna repercusión en la belleza de la ciudad, símbolo de la grandeza de Roma. Creo que en ese momento, siglo I d.C., el Senado principalmente tuvo en consideración razones económicas, como eran la especulación inmobiliaria y el incontrolado mercado de materiales de edificación.

Marciano, entre finales del siglo II y principios del III, teniendo en cuenta solo las edificaciones urbanas, reconoce una excepción a la prohibición contenida en estos senadoconsultos, en virtud de la cual se permitía la venta de mármoles y columnas para su posterior empleo en edificios públicos (Dig. 39,2,48 [Marcian. de delat.]: Si quis ad demoliendum negotiandi causa vendidisse domum partemve domus fuerit convictus: ut emptor et venditor singuli pretium, quo domus distracta est, praestent, constitutum est. ad opus autem publicum si transferat marmora vel columnas, licito iure facit).

Para Robinson, esta excepción a la norma pone de relieve que eran motivos estéticos los que inspiraban tal prohibición de demolición ${ }^{27}$. A mi juicio, sin embargo, más que un preocupación por el aspecto de las ciudades, que ciertamente puede intuirse, se trata de una medida que expresa la cada vez mayor presencia de lo público sobre lo privado. Pues, si fuera solo una motivación estética, no se habría consentido que casas particulares fuesen demolidas y privadas de sus principales elementos de exorno.

Los senadoconsultos Hosidiano y Volusiano presentaban, en cualquier caso, una limitación: solo afectaban a edificios demolidos para ser transmitidos por actos inter vivos, como la compraventa. De ahí que, algunas décadas después, una disposición de Adriano, dada bajo la forma de senadoconsulto, extendió a los actos mortis causa el contenido de los dos anteriores, el Hosidiano y el Volusiano. Este nuevo senadoconsulto recibió el nombre de Aciliano y declaró la nulidad de los legados que implicaran la separación de elementos de la domus (Dig. 30,114,9 [Marcian. 8 inst.] $)^{28}$ :

Aedes destruendae neque legari neque per fideicommissum relinqui possunt: et ita senatus censuit.

A juicio de Murga, una de las más importantes innovaciones de esta norma fue que la prohibición existía con independencia del ánimo de lucro de quien retiraba los mármoles, relieves y columnas de los edificios, ya que los legados se hacían con ánimo de liberalidad y con ellosse buscaba obtener un enriquecimiento. Sin embargo, se recogía una excepción: que la separación fuera para trasladar dichos elementos a otro inmueble del mismo propietario y sin lucro (Dig. 30,1,4,1,3 [Ulp. 21 Sab.] $)^{29}$. Dicha posibilidad de transporte

\footnotetext{
27 Robinson (1996) p. 45.

28 Murga (1986) pp. 40-42, 46 y ss. considera que el punto de vista de Ulpiano difiere del de Papiniano recogido en Dig. 30,41,5 (Ulp. 21 Sab.), donde este último defiende que, si los adornos eran retirados para su utilización en un edificio público, no se contravenía la prohibición del senadoconsulto Aciliano. Para Ulpiano, era indiferente que el destino fuese privado o público. Cfr. también al respecto Dig. 30,41,1/3/6/8/9; 43 pr. (Ulp. 21 Sab.).

29 Murga (1976) pp. 42-44. La ratio legis de este senadoconsulto fue impedir la destrucción de las ciudades, que ya comenzaba a ser evidente y que se consumaría siglos más tarde. Sin embargo, Garnsey (1976) pp. 134 y
} 
habría estado precedida, en el ámbito de los actos inter vivos, por unedicto de Vespasiano, que no nos ha llegado y del que sabemos indirectamente, a través de una constitución imperial del año 222 (CJ. 8,10,2):

Imperator Alexander Severus. Negotiandi causa aedificia demoliri et marmora detrahere edicto divi Vespasiani et senatus consulto vetitum est. Ceterum de alia domo in aliam transferre quaedam licere exceptum est: sed nec dominis ita transferre licet, ut integris aedificiis depositis publicus deformetur adspectus ALEX. A. DIOGENI. (A. 222 PP. XI K. IAN. ALEXANDRO A. CONS.)

Ahora bien, a mi entender, dicha constitución, dada por el emperador Alejandro Severo a Diógenes, es importante en el estudio que nos ocupa por otro motivo. En ella, a propósito de la prohibición establecida en los senadoconsultos Hosidiano y Volusiano y en el arriba citado edicto de Vespasiano, alega una razón de carácter estético para conservar la integridad de los edificios (publicus deformetur adspectus). Gómez Buendía señala cómo este interés por preservar el paisaje urbano existió también entre la jurisprudencia (Dig. 43,8,2,17 [Ulp. 68 ed.], Dig. 43,8,7 [ Iul. 48 dig.] ] $)^{30}$. A este respecto, considero oportuno señalar que, aunque fue en el período de los Severos en el que empezó a hablarse abiertamente de la estética urbana, la preocupación por la misma habría comenzado ya algún tiempo antes. Así se desprende un fragmento de Juliano (Dig. 43,8,7 [Iul. 48 dig.]), jurista de principios del siglo II, a propósito de la prohibición de demolición de edificios construidos en lugar público (ne ruinis urbs deformetur) ${ }^{31}$ :

Sicut is, qui nullo prohibente in loco publico aedificaverat, cogendus non est demolire, ne ruinis urbs deformetur, ita qui adversus edictum praetoris aedificaverit, tollere aedificium debet: alioqui inane et lusorium praetoris imperium erit.

Ulpiano, jurista que fue consejero y prefecto del pretorio de Alejandro Severo, se expresa de forma similar, alegando el factor estético para impedir la demolición de un edificio, aun cuando se hubiese levantado en un lugar público (Dig. 43,8,2,17 [Ulp. 68 ed.]). Si bien, sitúa por encima de este elemento otro de mayor valor, el uso público. En efecto, este fragmento de Ulpiano pone de relieve cómo era posible construir en lugares considerados como públicos, siempre que nadie lo hubiera prohibido y la edificación no estorbara al uso público $^{32}$. Si así fuera, debería ser derribada, a menos que se pagara por el arrendamiento del inmueble una renta pública fija, denominada solarium ${ }^{33}$ :

ss. opina que estas medidas no tenían nada que ver con el declive de la actividad agrícola y el abandono de las ciudades. Su interés son los edificios y, más en concreto, los edificios urbanos.

30 Gómez Buendía (2013) p. 217 y ss.

31 Ahora bien, tratándose de vías públicas, PONTE (2007) p. 186, considera que la construcción debía ser demolida en cualquier caso, pues era necesario que estuvieran despejadas para el tráfico.

32 Zoz (1999) p. 179 señala cómo, además de la razón estética, otro motivo por el que no procedía el interdicto demolitorio en caso de que la edificación se hubiera concluido sin que nadie lo hubiera prohibido, era que dicha orden no tenía carácter restitutorio.

33 Liebeschuetz (2000) p. 60 pone de relieve cómo entre toda la regulación urbanística destaca la preocupación por las construcciones realizadas por particulares en espacios públicos. A lo largo de toda la época imperial estas usurpaciones de terreno fueron frecuentes. Fuentes como Dig. 43,8,2,17 (Ulp. 68 ed.) y CJ. 8,11,3 reconocen esta realidad, no querida, pero permitida en algunos casos cuando servía para embellecer la ciudad. En otros, sin embargo, estas construcciones eran demolidas (CJ. 8,11,14). Sobre las construcciones realizadas 
Si quis nemine prohibente in publico aedificaverit, non esse eum cogendum tollere, ne ruinis urbs deformetur, et quia prohibitorium est interdictum, non restitutorium. Si tamen obstet id aedificium publico usui, utique is, qui operibus publicis procurat, debebit id deponere, aut si non obstet, solarium ei imponere: vectigal enim hoc sic appellatur solarium ex eo, quod pro solo pendatur.

En mi opinión, lo realmente significativo de esta fuente es el establecer una jerarquía de intereses merecedores de protección, a la cabeza de los cuales se sitúa el uso que cada ciudadano puede hacer de las cosas públicas, siempre que no haga imposible el de los demás. Por otra parte, considero que tanto este texto como el de Juliano anteriormente citado, al recoger como presupuesto para evitar la demolición del edificio el que nadie se hubiera opuesto a su realización (qui nullo prohibente in loco publico aedificaverat [Dig. 43,8,7 (Iul. 48 dig.)]; Si quis nemine prohibente in publico aedificaverit [Dig. 43,8,2,17 (Ulp. 68 ed).]), están reconociendo la capacidad de los individuos, miembros de la comunidad de ciudadanos, para tutelar el uso y disfrute que tenían de los bienes y lugares públicos. En este sentido, cabe señalar cómo a juicio de Terrazas, res publicae era un término equivalente a res populi, de ahí que se emplee tanto para hacer referencia a los bienes de uso público como a aquellos otros que se encuentran in patrimonio populi o in patrimonio fisci, de los cuales puede obtenerse un aprovechamiento patrimonial (tierras, esclavos públicos y dinero). Ahora bien, no todas las cosas públicas estaban sometidas a un mismo régimen jurídico. En sentido estricto, pues, solo serían propiamente res publica las cosas de las que puede hacer uso cualquier ciudadano (puertos, costas, ríos perennes); las cuales, por otra parte, no eran susceptibles de apropiación privada y solo tenían defensa interdictal ${ }^{14}$. Zoz,

en lugares públicos y la obligación de demolición cuando obstaculizaran el uso público, a menos que se pagara el solarium, cfr. BARCKHAUSEN (1860) p. 42. El autor señala cómo, no obstante, las edificaciones levantadas en lugares sagrados merecían un tratamiento distinto: se prohibía construir y la demolición no podía ser evitada a través de una determinada suma de dinero, ya que las cosas sagradas no eran susceptibles de valoración patrimonial. Zoz (1999) pp. 68-70 destaca cómo, en el supuesto de conservarse la edificación por cumplirse los requisitos expuestos por Ulpiano en el fragmento, se procedía a cobrar un vectigal al particular que la había levantado.

34 Terrazas (2010) pp. 151 y ss., 154-157. Este tipo de bienes no debe ser confundido con las cosas que por derecho natural son comunes a todos los hombres, ciudadanos o no, las res communes omnium, cuyo uso no se podía prohibir ni regular. Una tercera modalidad serían las res universitatis, que pertenecían a las ciudades, como por ejemplo los teatros. En Derecho justinianeo, señala el autor, los tres sentidos del término se subsumieron en uno solo con igual régimen jurídico. Sin embargo, los juristas de época clásica establecen diferencias entre ellos. Este autor entiende que el criterio fundamental observado en Derecho Romano para establecer la clasificación de las cosas es el de la pertenencia y, en consecuencia, la legitimación o no a la acción reivindicatoria. Terrazas pone de relieve cómo fue Celso (Dig. 43,8,3 pr.-1 [Cels. 39 dig.]) el primero que advirtió la diferente naturaleza del mar y las costas en relación con otras res publica. Sin embargo, no fue el único. Más adelante, también la pondrán de manifiesto Paulo (Dig. 18,1,34,1 [Paul. 32 ed.]; Dig. 18,1,51 [Paul. 21 ed.]) y Ulpiano (Dig. 39,1,1,17-18 [Ulp. 10 ed.], Dig. 43,1,1 pr. [Ulp. 10 dig.], Dig. 43,8,2,8 [Ulp. 68 ed], Dig. $48,8,2,2$ [Ulp. $68 \mathrm{ed}$.]). Sobre todo, este último profundizará sobre las res universitatis. En consecuencia, la distinción que Marciano realiza, recogida en Dig. 1,8,2 (Marcian. 3 inst.), en la que menciona expresamente las cosas comunes por derecho natural, las res universitatis o que pertenecen a la colectividad, las res nullius y las cosas que pertenecen a los particulares, según Terrazas, no es tan novedosa como en principio pudiese parecer. Este autor atribuye al error de un copista el hecho de que la clasificación de las cosas que hace Marciano no incluya las res publica. En este sentido, Zoz (1999) pp. 63-66, 79, 194 considera que Marciano debía conocer perfectamente la categoría de res publica, dentro de la cual habrían estado también incluidas, en un primer mo- 
por su parte, considera que, en el supuesto de los bienes públicos, su utilidad era uti cives y, en consecuencia, el interés propio del particular se valoraba en función de los intereses de la colectividad a la que pertenecía la cosa ${ }^{35}$.

En cualquier caso, es importante destacar que la constitución de Alejandro el Severo, tal y como Murga pone de relieve, representa un importante avance en el intervencionismo público por la defensa del bien común, ya que por primera vez una norma recoge la concepción del edificio como unidad, algo que hasta entonces solo había sido intuido por la Jurisprudencia, y limita las facultades de disposición de su propietario cuando con ello se causaba un perjuicio a la estética urbana ${ }^{36}$. Según Murga, esta norma supone, en concreto, la adopción de un planteamiento moderno y social resultado de una evolución, política y jurídica, de muchos siglos. Preocupaciones latentes en épocas pasadas se expresan de manera abierta en esta constitución imperial que pone de manifiestocómo estamos ante una concepción del ius publicum diferente de la que se había tenido hasta ese momento. A su juicio, hasta el siglo II, el interés público era considerado como interés popular; por tanto, cívico y no estatal. Por ese motivo se reconocía para su defensa una acción con legitimación activa abierta a cualquier particular que, como miembro de la comunidad de ciudadanos, se considerase perjudicado. El proceso que se iniciaba con la interposición de este tipo de acciones era privado, lo que indica que la tutela del interés público se hacía a través de la defensa de los derechos de los particulares ${ }^{37}$. Casavola, sin embargo, nos ofrece un concepto

mento, las cosas comunes. Los juristas habrían usado ambos términos sin demasiado rigor, de ahí que los textos donde aparecen deban ser tratados con cierta cautela. A su juicio, originariamente, para hacer referencia a cosas que no eran ni privadas ni divini iuris, solo se habría hablado de res publica. A continuación, se habría distinguido dentro de estas entre res in usu populi y res in patrimonio populi. Más adelante, hubo juristas que vieron cómo algunas de estas cosas eran públicas iure gentium y, posteriormente, llegaron a diferenciar entre las cosas que eran del "Estado" y las que eran de la ciudad. Sobre las res publicae y su diferencia con la res universitatis y la res communes omnium, cfr. PONTE (2007) pp. 55-68.

35 Zoz (1999) pp. 9-11, 68-70, 183-185, 187-190. En sentido estricto, solo serían res publicae los bienes inmuebles pertenecientes al pueblo romano y de uso público que ningún particular podía adquirir. Estos bienes se distinguen de aquellos otros in patrimonio populi que, aunque pertenecían al populus Romanus o bien a colonias y municipios, se sustraían del uso público y se obtenía de ellos un rendimiento económico. De hecho, eran magistrados diferentes los que cuidaban de cada uno de ellos: en el primer caso, los censores; en el segundo los cuestores. La autora sostiene que, dentro de las cosas públicas había algunas que lo eran por naturaleza (res communes), otras como consecuencia de un acto de publicatio, y otras que lo eran, sin embargo, por su destino, como por ejemplo los bienes de titularidad privada, pero de uso público. En su opinión, debido a que la utilidad de las cosas comunes era individual, el Estado consentía que su defensa se hiciera a través de recursos privados, pues se trataba, en definitiva, de relaciones entre particulares; en el caso de las cosa públicas, sin embargo, su uso era colectivo y, por tanto, solo de forma excepcional se acudía a la tutela privada. Lo habitual fue que, desde el poder público, se emplearan recursos como la denuncia de obra nueva, la vindicatio in publicum, interdictos, sanciones y multas e incluso la intervención directa de los magistrados. Cfr. especialmente p. 197, donde la autora pone de relieve cómo, en un primer momento, no tenía sentido hablar de propiedad o soberanía sobre las cosas de uso público, porque se consideraba que el populus y todos los ciudadanos tenían sobre ellas una especie de condominio.

36 Murga (1986) p. 52. A juicio de este autor, fue la influencia helenística la que introdujo las cuestiones de índole urbanística en el ámbito jurídico. Murga (1976) p. 78. En el mismo sentido se expresa Robles (2001) p. 186, para quien esta constitución pone de relieve la existencia de una tendencia limitadora de la especulación y los intereses patrimoniales privados a favor del bien público.

37 Murga (1976) pp. 64-67 y n. 112. Murga, a propósito de las acciones populares, llama la atención sobre el hecho de que se trata de acciones de carácter procuratorio, pero donde no se actúa en nombre de otro, sino en 
de lo popular distinto. Para este autor, lo privado era lo que correspondía a la familia, lo público al estado y lo popular a cada individuo (singularis homo). Las acciones populares no eran acciones con legitimación activa general, sino acciones que se caracterizaban porque la legitimación activa a la acción se adquiría por la mera condición de ser unus ex populo, con capacidad para usar las res publicae. De tal modo que, si este uso era impedido, consideraban que se estaba lesionando un ius suum, ya que afectaba al entorno urbano común en el que desarrollaban su actividad cotidiana ${ }^{38}$.

Probablemente, hasta el siglo II no fue necesaria una intervención mayor por parte de los poderes públicos ni se contaban con los instrumentos procesales para ello. Todo esto cambió en el siglo III, cuando se acentúa el papel del gobierno imperial en todos los ámbitos, incluso en aquellos que hasta ese momento habían sido considerados como privados. Las acciones populares se van a interponer para defender intereses colectivos, los cuales se sitúan a medio camino entre lo privado y lo público. Los particulares que interponen una demanda de esta naturaleza defienden un interés privado.

Por último, y para concluir este recorrido legislativo, cabe señalar que, más adelante, en el 321, el emperador Constantino prohibió el traslado de materiales ornamentales de la ciudad a las villas del campo (CJ. 8,10,6 pr.):

Imperator Constantinus. Si quis post hanc legem civitate spoliata ornatum, hoc est marmora vel columnas, ad rura transtulerit, privetur ea possessione, quam ita ornaverit. CONST. A. HELPIDIO AGENTI VICEM PP. (A. 321 D. VI K. IUN. VIMINACII CRISPO II ET CONSTANTINO II CONSS).

Garnsey, que ha analizado las leyes de Tarento, Osuna y Málaga en relación con los senadoconsultos Hosidiano y Volusiano, considera que, aparte del hecho de su distinto ámbito de aplicación (más amplio el de estos dos últimos), otras diferencias son especialmente significativas. Entre ellas, destaca que los senadoconsultos impiden las demoliciones de edificios seguidas de una venta, mientras que las leyes municipales persiguen directamente el acto de demolición ${ }^{39}$. Murga sostiene que los senadoconsultos Hosidiano y Volusiano intentaron conservar la unidad de los edificios romanos, prohibiendo que se especulara con ellos con el fin de ser desguazados. Pues, como destaca este autor, no solo sus elementos más bellos (estatuas, frisos, relieves, columnas, mármoles) eran retirados sino también otros como cañerías, depósitos, tejas, etc. Murga considera que el espíritu que impregnaba la regulación imperial era fundamentalmente el de la conservación de la belleza y la armonía de

el propio para defender un derecho propio, aun cuando no exclusivo. También sobre la naturaleza procuratoria de las acciones populares, D’Ors (1953) p. 161. No obstante, LEwis (1989)pp. 53s., señala cómo el hecho de que la ley de Osuna implique directamente a los magistrados municipales en el control del tipo de reedificación que se haga demuestra cómo en ese momento existía ya una preferencia por la defensa del interés común en relación con los intereses privados.

38 Casavola (1958) pp. 15-18.

39 Véase Garnsey (1976) pp. 133 y ss. Según este autor, lo más interesante de la ley de Tarento es que permitía que la demolición se llevaba a cabo si era para mejorar el estado de la construcción; de la ley de Urso destaca cómo establecía una fianza que se perdía si el edificio no era reconstruido; y de la Malacitana, la introducción de un plazo de un año para realizar la restauración del inmueble. A su juicio, a finales de la República, en Roma debió existir una regulación en esta línea, aunque no nos hayan llegado testimonios. Cfr. también el análisis que, de los textos epigráficos y de los emanados del Senado, lleva a cabo Robinson (1996) pp. 42 y ss. 
los edificios. Sin embargo, fuera de Roma, la motivación pudo ser otra: evitar el abandono y expolio de comunidades más pequeñas que, poco a poco, estaban quedando deshabitadas. Con el tiempo, la floreciente vida de muchos municipios fue disminuyendo como resultado de la asfixiante política imperial que, con su burocracia y centralización, acabó con la anterior organización administrativa ${ }^{40}$. En definitiva, se produjo un enfrentamiento de intereses privados y públicos que, en época severiana, Ulpiano resolvió definitivamente a favor de estos últimos ${ }^{41}$. Sin embargo, a juicio de Lewis, la razón de la existencia de estas prohibiciones de demolición hay que buscarla en la protección de la estética del entorno urbano (urban environment) y en el interés social por mantener un cierto número de viviendas disponibles. Se evitaba de esa manera que los edificios urbanos fueran derribados para embellecer las casas, muchas de ellas situadas en el campo y rodeadas de hermosos jardines y comodidades. A juicio de Lewis tales prohibiciones serían una expresión coherente del espíritu romano, no muy dado a las muestras de ostentación y lujo ${ }^{42}$.

En mi opinión, las fuentes romanas y municipales ponen de relieve cómo existió, desde muy antiguo, un claro interés por evitar que los edificios fueran demolidos; si bien las motivaciones que en cada período histórico se tuvieron evolucionaron. De ahí que, en algunos textos legales se ponga el acento en la necesidad de reedificación inmediata del inmueble para poder derribarlo; en otros, la prohibición se vincule a la finalidad de obtener un enriquecimiento con la venta del edificio o de sus materiales; o bien, se señalen razones de índole estético para impedir su derribo. Con independencia de estos intereses, fuertemente ligados al momento histórico en el que encuentran abrigo, la constante que observamos en estos textos se encuentra, a mi modo de ver, en una preocupación por los inconvenientes que la generación de escombros sin control podía dar lugar. Por encima de todos, el mayor problema, ya señalado por la Tabula Heracleensis y, posteriormente, abiertamente defendido por Ulpiano (D. 43,8,2,17 [Ulp. 68 ed.]), era que impedían el adecuado uso de los lugares públicos por parte de los individuos que integraban la comunidad de ciudadanos. Esta es la razón principal por la que se conceden acciones populares e interdictos para

\footnotetext{
40 Murga (1986) pp. 35, 44s., 48-50. Murga considera que, probablemente, frente la política antimunicipal que desde la Urbe se estaba realizando a favor de ciudades más grandes, Ulpiano decidió defender los intereses de los pequeños municipios y evitar su desmantelamiento. Con ello el jurista se habría adelantado, casi un siglo, a la situación de expolio, casi generalizado, de un amplísimo número de núcleos urbanos que, a partir del siglo IV, adquirió una especial gravedad. A juicio de Garnsey, de estos dos senado consultos lo único que se puede deducir es que había una preocupación notable por conservar la estética urbana a través de la prohibición de demolición de sus edificios más hermosos. Ese interés no era el mismo cuando se trataba de construcciones de menor nivel situadas en los arrabales de la ciudad. Véase GARnSEY (1976) pp. 134-136. A este respecto cabe señalar cómo, según destaca Robinson (1996) pp. 20 y ss., 44, la política de la dinastía Flavia fue la de reconstruir la ciudad y los desastres que la guerras habían producido sobre ella, ordenándose obras como el Coliseo o devolviendo el distrito de la via Sacra al pueblo. Posteriormente también destacará Adriano por levantar numerosos edificios alrededor de todo el imperio. Asimismo esta autora no considera que esta normativa prohibitoria estuviera motivada por el interés de los poderes públicos en mantener un número suficiente de viviendas disponibles en Roma, sino por cuestiones de índole estético, pues protegiendo la belleza de la Urbe se intentaba preservar su grandeza y gloria.

41 Sobre la tensión entre lo público y lo privado que se aprecia en materia urbanística, MalaVé (2011) p. 335.

Esta autora observa como esta sigue siendo, también en la actualidad, una de sus notas características.

42 LEWIS (1989) p. 48.
} 
intervenir en caso de que una edificación ponga en riesgo dicho modo limitado de aprovechamiento. Los escombros son vistos en sí mismos como un importante problema, pues representan un obstáculo para la convivencia ciudadana. Aparte de los daños indirectos que podían causar (medioambientales, estéticos o de especulación inmobiliaria), su presencia interfería sobre la calidad del disfrute que los ciudadanos tenían de los espacios públicos. Los escombros entorpecían el tránsito de las vías públicas y, en general, el modo de vida del que gozaban los habitantes de la ciudad, que veían a esta como entorno ideal para su desarrollo vital y expresión de la grandeza de un pueblo.

\section{LA DENUNCIA DE OBRA NUEVA}

Junto a las prohibiciones establecidas normativamente a las que acabamos de hacer referencia, existieron también otros instrumentos, voluntarios y de naturaleza privada, que sirvieron para impedir la demolición de edificios de forma incontrolada y, en consecuencia, limitar la generación de escombros. Entre ellos destaca la denuncia de obra nueva ${ }^{43}$. El edicto del pretor preveía la posibilidad de parar una obra mediante la interposición de dicha denuncia, que solo podría continuarse si se daba una caución como garantía (Dig. 39,1,1 pr./9 [Ulp. 52 ed.]). A juicio de Santucci, la función original de la novi operis nuntiatio fue la de defender las servidumbres prediales de un eventual daño jurídico que pudiera derivarse de la realización de una obra de construcción o demolición llevada a cabo en el fundo sirviente. Solo con posterioridad, la denuncia de obra nueva pasaría del ámbito privado al público, empleándose para proteger intereses colectivos cuando un opus novum lesionaba el interés general ${ }^{44}$.

A mi modo de ver, es probable que la defensa del estado originario del inmueble objeto de una servidumbre fuera una de las más importantes razones por las que, en un primer momento, se establecieron limitaciones a las obras de demolición. De hecho, las leyes municipales, como por ejemplo la de Tarento, reconocían en este sentido, como excepción a la prohibición de derribo, que la obra fuera solo de restauración. Lo cierto es que, de acuerdo con Dig. 8,2,11 (Ulp. 1 de off. proc.), la conservación del edifico en su forma inicial, para respetar el uso limitado al que tenía derecho el fundo dominante, era imprescindible si se quería realizar cualquier tipo de obra en el mismo:

Qui luminibus vicinorum officere aliudve quid facere contra commodum eorum vellet, sciet se formam ac statum antiquorum aedificiorum custodire debere.

La operis novi nuntiatio se subdividía en tres tipos diferentes (Dig. 39,1,1,16 [Ulp. $52 \mathrm{ed.]):} \mathrm{la} \mathrm{operis} \mathrm{novi} \mathrm{nuntiatio} \mathrm{iuris} \mathrm{nostri} \mathrm{conservandi} \mathrm{causa,} \mathrm{que} \mathrm{servía} \mathrm{para} \mathrm{defender} \mathrm{un}$ derecho de servidumbre predial; la operis novi nuntiatio depellendi causa, si se trataba de

\footnotetext{
43 A propósito de la operis novi nuntiatio, véase las consideraciones que sobre la misma hacemos en CASTRO (2009) pp. 193-208, algunas de cuyas conclusiones son tenidas en cuenta, parcialmente, en este trabajo. Asimismo, cfr. KARlOWA (1901) pp. 471-479, 1225-1233; JimÉNEZ (1999) pp. 225-234.

44 SAntucci (2001) pp. 4s., 84-93, 162. Su ventaja, frente a la defensa interdictal, consistía en que tenía una tramitación sencilla y eficaz. El autor señala en este trabajo, en el que realiza un interesante estudio palingenésico de las obras de Labeón, Ulpiano y de Sexto Pedio al respecto, cómo la causa nuntiationis podía ser triple: natura, lex publicalius civile, lex privata (Dig. 39,1,5,8-10 [Ulp. 52 ed.]).
} 
De CASTRo-Camero, Rosario $\square$ Medidas para prevenir la producción de escombros...

impedir un daño; y la operis novi nuntiatio tuendi gratia, cuando el objetivo era proteger un interés público:

Nuntiatio fit aut iuris nostri conservandi causa aut damni depellendi aut publici iuris tuendi gratia.

Siguiendo a Branca, hay que señalar que solo tenían en común el hecho de darse ante un opus novum. Ente sus diferencias, destaca el tipo de caución que les seguía. En los supuestos de operis novi nuntiatio iuris nostri conservandi causa y de operis novi nuntiatio tuendi gratia, la cautio ex operis novi nuntiatione; en el de la operis novi nuntiatio depellendi causa, la cautio damni infecti. Por otra parte, era también distinto lo que se perseguía con cada una de ellas: en el primer caso, la paralización de la obra; en el segundo, su demolición; y, en el último, el resarcimiento del daño ${ }^{45}$. Según Jiménez, la operis novi nuntiatio iuris nostri conservandi causa fue la que dio lugar a las otras dos. La operis novi nuntiatio tuendi gratia tiene su origen en torno al siglo I d.C.; la operis novi nuntiatio damni depellendi causa es de la segunda mitad del siglo II. Una de las principales diferencias entre una y otra estaría referida a la legitimación activa: en el primer caso, era popular, cualquier ciudadano podía solicitarla; en el segundo, sin embargo, estaba limitada a aquellas personas legitimadas a la cautio damni infecti, pues para alejar la amenaza de un daño temido lo procedente era, mejor que paralizar la obra, solicitar dicha caución y obtener una garantía frente a un eventual perjuicio ${ }^{46}$. Según Paricio, la operis novi nuntiatio damni depellendi causa habría

45 Branca (1937) p. 328. En relación con el tipo de construcción susceptible de ser objeto de una denuncia, señala GLÜCK (1903) pp. 20 y ss. que se tenían en cuenta no solo las obras levantadas desde los cimientos, sino también las que consistían en la ampliación de otra ya existente y las realizadas con la finalidad de destruir total o parcialmente una construcción. Asimismo se consideraba como obra nueva el edificio que era reedificado y recuperaba el aspecto que inicialmente había tenido, antes de su derrumbamiento. Por el contrario, calificado de opus novum una obra que fuera solo de mantenimiento o de reparación y que no modificara el primitivo aspecto de la edificación. Para Jiménez (1999) pp. 227 y ss, por opusnovum cabía entendertoda alteración del estado primitivo de un lugar, realizada tanto por una actividad de construcción como de demolición. Sin embargo, las modificaciones de un fundo que no afectasen a su suelo, como por ejemplo, la recogida de la cosecha, la tala de árboles o la poda de unas viñas, no serían consideradas como tal, así como tampoco los casos de restauración del edificio que no supusieran un cambio de su estructura original (Dig. 39,1,1,13 [Ulp. 52 ed.]). En principio, como señala MELCHOR (2010) p. 37, no era necesaria ninguna autorización para levantar una obra nueva, a menos que se tratara de las siguientes obras públicas: un teatro, un circo o un anfiteatro. Sobre los motivos por los que este tipo de construcciones públicas y no otras requirieron de control público, cfr. pp. 38-40. Melchor considera que probablemente fuera por razones de seguridad, al tratarse de edificaciones destinadas a albergar a gran cantidad de personas. Por otra parte también se tenía en cuenta el mantenimiento que tales instalaciones acarreaba. Este correspondía a las arcas municipales, aun cuando hubieran sido construidos por iniciativa de un particular como acto de evergetismo. Un claro ejemplo de ello lo tenemos en la nova urbs de Itálica, donde podemos ver cómo la fachada sur de su anfiteatro está inacabada al ser imposible para la colonia obtener los fondos necesarios para su conservación. Acerca de la exigencia de licencia urbanística en numerosas obras públicas, realizadas a través de contratos, sobre todo a partir del s. V, Rodríguez-López (2011) pp. 393-408. En relación con la obligación de solicitar licencia de construcción en el vigente Derecho español, cfr. AlCÁZAR (2010) pp. 57-60.

46 Jiménez (1999) pp. 226 y ss. también Murga (1976) p. 68. A su modo de ver, un siglo antes de lo que habitualmente se considera, la denuncia de obra nueva tuendi gratia sirvió para defender el interés público. El verbo tueri, señala Murga, hacía referencia a la defensa procesal de un interés privado, pero también se empleaba cuando se trataba de la defensa de valores políticos, sociales, colectivos o urbanos, como la paz, la dignidad o la salud de la res publica. Cfr. en tal sentido Dig. 3,1,1 pr. (Ulp. 6 ed.); Dig. 1,12,1,12 (Ulp. sing. de off. praef. urb.); Dig. 1,15,3 (Paul. sing. de off. praef. vig.). Otro ejemplo de defensa de lo colectivo a través de la interposición de 
aparecido en un momento posterior al tiempo de Sexto Pedio y anterior a Ulpiano. A diferencia de las otras dos, no habría dado lugar a la paralización inmediata de la obra. Al presentarse la denuncia y solicitarse la caución, opina este autor, lo único que se quiere es obtener una garantía para el caso de producirse eventualmente un daño patrimonial con la obra que se está realizando ${ }^{47}$.

La operis novi nuntiatio iuris publici tuendi gratia se esgrimía contra cualquiera, incluido el dominus, que no observase la prohibición legal y se llevara elementos de un edificio. Ahora bien, lo interesante de este recurso es que ya no se trataba de una acción privada que se interponía para defender un interés colectivo o popular a través de un procedimiento privado ordinario, sino de una denuncia con la que se iniciaba una serie de actuaciones públicas, basadas en el imperium del magistrado. Al reconocerse a cualquier particular la legitimación activa para su interposición, originariamente reservada a quienes veían lesionados sus derechos con esa construcción, fue utilizándose progresivamente en la defensa de otros intereses, primero de carácter colectivo y, más tarde, públicos ${ }^{48}$. El interés público será la suma de todos esos intereses privados, que terminará concretándose en un interés distinto, un bien jurídico digno de protección diferente a la mera conjunción de varios intereses particulares. Cuando esto sucede, empiezan a defenderse valores superiores, que antes solo eran intuidos, pero que a partir de ese momento van tomando forma. Ese salto de lo privado a lo público es trascendental, porque supone abrir el Derecho a una nueva esfera de bienes dignos de protección. Ahora bien, para alcanzar este punto fue necesario que previamente se desarrollara el sentido de lo colectivo, lo que es de todos y cada uno de los individuos que integran la comunidad, esto es, lo popular. El que el proceso privado estuviera abierto también a la interposición de acciones populares demuestra cómo el pueblo

un recurso con legitimación activa privada son los interdictos. En efecto, según GANDOLFI (1955) pp. 25, 27-29, aunque el origen de los interdictos hay que situarlo en la defensa del uso de las cosas públicas, eran instrumentos puestos a disposición de los particulares para proteger sus intereses privados y, de forma indirecta, los de la colectividad. De tal forma que, si un ciudadano realizaba un acto abusivo sobre un bien de la comunidad y nadie se lo prohibía, el magistrado no podía intervenir con una orden de este tipo. A propósito de la diferencia entre la operis novi nuntiatione depellendi causa, con la que se busca solo obtener una indemnización por el daño temido si llegara a producirse, y las otras dos, en las que propiamente el objetivo es una restitución de la obra,cfr. GLƯCK (1903) pp. 316 y ss. Este autor profundiza también entre las diferencias existentes entre la denuncia de obra nueva iuris nostri conservandi causa y la interpuesta iuris publici tuendi gratia. En el primer caso, el propietario que levantaba la obra y daba caución, mientras el denunciante no probara el ius prohibendi, podría interponer el interdicto ne vis fiat aedificanti. Sin embargo, en el caso de la denuncia tuendi causa, no era posible.

47 A juicio de PARICIO (1982) pp. 474, 477-479, no había posibilidad de remissio de la denuncia por parte del pretor porque esta se basaba en la existencia de un ius prohibendi del denunciante. Cuestión que, en el caso de la operis novi nuntiatio damni depellendi causa, no era relevante, ya que la denuncia era independiente de que existiera o no legitimidad para realizar la obra. Por otra parte, cabe señalar que, en Dig. 39,1,5,9 (Ulp. 52 ed.), Ulpiano cita a Sexto Pedio, para quien entre las tres causas (natural, pública o por derecho de servidumbre) que podían dar lugar a una denuncia de estas características no estaba la de evitar un daño, sí mencionada por Ulpiano en Dig. 39,1,1,16 (Ulp. 52 ed.).

48 Murga (1986) pp. 52 y ss., Luzzatto (1965) p. 242 defiende que tuvo una legitimación activa muy amplia, de forma que quien se sintiera amenazado en su derecho por una obra podía exigir que esta se parara hasta que no se garantizara adecuadamente que tal derecho sería respetado. Señala este autor que, a pesar de ser la nuntiatio o denuncia un instrumento de carácter privado, el ordenamiento jurídico le proporcionó reconocimiento al contemplar determinados recursos oportunos, como cauciones e interdictos, para hacer eficaz su interposición. 
romano no concibió sus instituciones con rigidez o carácter cerrado. A través de una larga evolución, de lo privado se pasó a lo colectivo y finalmente a lo público y, en consecuencia, a medida que se desarrollaba el poder imperial como fuente de todo poder y derecho, este tipo de intereses defendiendo en procedimientos extraordinarios (cognitio extra ordinem), de naturaleza claramente pública. A este respecto, debemos traer a colación la opinión de Carvajal, quien a propósito de la diferencia entre bien público y bien común pone de relieve cómo el primero hace referencia al bien de un cuerpo social organizado y el segundo, por su parte, no es una mera agregación de res privata. A su juicio, el elemento que define al bien común de carácter cualitativo, no cuantitativo, caracterizándose por buscar la mayor realización de la persona, tanto en lo material como en lo espiritual. De ahí que no siempre coincida con el bien público ni con la suma de todos los intereses privados de una comunidad $^{49}$.

Una vez vista la cuestión de los tipos de denuncia que cabría presentar, conviene examinar qué sucedía tras su admisión. Para poder continuar la obra, en nuestro caso de demolición, se exigía la prestación de una caución, la cautio ex operis novi nuntiatione. Esta era una estipulación en virtud de la cual, como destaca Jiménez, el promitente, el llamado nuntiatus, se comprometía a dejarlo todo como estaba antes de la interposición de la denuncia ${ }^{50}$. En el supuesto de que se tratara de una obra nueva construida por varios propietarios, todos ellos debían dar la caución, ya que no era posible la demolición parcial de la obra si se producía efectivamente la lesión del derecho del denunciante (Dig. 39,1,21,5 [Ulp. 80 ed.]). Si no se daba la caución ni el pretor decretaba la remissio y el denunciado continuaba la obra, el magistrado daba el interdicto demolitorio ${ }^{51}$. Este interdicto, que según Glück tenía carácter restitutorio y legitimación popular, obligaba a derribar todo lo construido. Su fórmula habría sido la siguiente ${ }^{52}$ :

Quem in locum nunciatum est, ne quid operis feerit, qua de re agitur, quod in eo loco, antequam nunciatio nissa fieret aut in ea causa esset, ut remitti deberet factum est, id restituas.

\footnotetext{
49 Carvajal (2013) pp. 376-378. Este autor pone de relieve cómo los ciudadanos (cives) fueron los que dieron lugar a la ciudad (civitas) y no al revés. A su juicio, conviene traducir cives como "conciudadano", ya que es un término que necesariamente tiene sentido solo en relación a otros. En consecuencia, por cives ha de entenderse un conjunto de personas que se constituye políticamente como ciudad. En la misma línea se expresa ZoZ (1999) pp. 170, 197 que considera igualmente la civitas como un agregado de cives. Acerca del concepto de populus, sostiene que, aunque con anterioridad a la jurisprudencia clásica se inicia su evolución, no llega a considerarse esta colectividad (universitas) como una entidad en sí misma, diferente a los singulares ciudadanos que la integran.

50 Jiménez (1999) pp. 227-230 subraya el carácter judicial de esta estipulación, lo que en opinión de GiOMARO (1983) pp. 425-427 no es tan evidente, dado que la nuntiatio es un acto privado que se desarrolla extrajudicialmente. A su juicio, su naturaleza es pretoria, tal y como se desprende del tipo de medida que se toma frente al nuntiatus si se niega a prestar la caución: el interdicto demolitorio. A propósito de los interdictos que se podían solicitar si no se daba caución después de la interposición de la operis novi nuntiatio (interdicto demolitorio) y en caso de su prestación (interdicto ne vis fiat aedificandi), cfr. BETANCOURT (1989) p. 127. Sobre el interdicto ne vis fiat aedificanti, cfr. LuZzATTO (1965) pp. 181-183, que lo sitúa dentro de la categoría de interdicta de operibus in solo factis, para los supuestos en que el que está realizando una obra nueva y ha sido denunciado, da caución.

51 Sobre los presupuestos que debían darse para que el pretor decretara el interdicto, véase GLÜCK (1903) p. 147.

52 Véase GlÜCK (1903) pp. 3, 146 y ss.
} 
Ahora bien, como Murga pone de relieve, tratándose de obras realizadas con la finalidad de destruir un edificio para separar sus materiales, el interdicto demolitorio no era la respuesta pretoria más adecuada, ya que de lo que se trataba era de paralizar la actividad que hasta entonces se había llevado a cabo, de marcado carácter negativo, y sustituirla por otra de signo positivo, a través de la cual el edificio recuperaría su estado original. A juicio de este autor, y dada la proximidad de la caución por la denuncia de obra nueva con la caución de daño temido, el recurso que se habría esgrimido contra el infractor que estaba demoliendo un edificio, era una missio in possessionem a favor del denunciante ${ }^{53}$. La proximidad existente entre la cautio ex operis novi nuntiatione y la cautio damni infecti ha sido puesta de manifiesto por numerosos autores ${ }^{54}$. Desde finales del s. I a.C., como señala Branca, la caución de daño temido no era obligatoria, pero sí muy habitual, en los casos en los que el daño temido provenía de una pared medianera (Dig. 39,2,43,1 [Alf. Var. 2 dig.] $)^{55}$. Por otra parte, tal y como explica Amunátegui, la sustitución del ambitus por la paries communis no supuso la desaparición del principio de no injerencia de terceros sobre los bienes propios. Este siguió vigente y solo podía ser limitado mediante la constitución de una servidumbre. Si esta no existía, el recurso jurisdiccional previsto era la actio negatoria ${ }^{56}$.

Tras todo lo expuesto, considero que se recurrió a la denuncia de obra nueva, para hacer eficaz la prohibición de demolición que las disposiciones senatoriales y otras normas establecieron con vistas a permitir el uso individual de los espacios públicos. El motivo por el que se recurrió a la denuncia para tal fin, a mi modo de ver, era que esta era el recurso que se había venido utilizando eficazmente para defender el uso limitado que un inmueble podía hacer de otro en virtud de un derecho privado de servidumbre. De ahí que cuando se planteó la cuestión de la tutela del uso colectivo de las cosas destinadas al disfrute de todos los miembros de la comunidad, se optara por ampliar los supuestos en que tal denuncia se concedía y se creara la operis novi nuntiatio publici iuris tuendi gratia. Por otra parte, hay que tener en consideración que la caución derivada de esta denuncia (ex operis novi nuntiatione), así como la cautio dani infecti, que se pedía en caso de denuncia damni depellendi causa se solicitaban para obtener una garantía ante un eventual daño jurídico o físico, respectivamente. Las obras de demolición de un edificio podían dificultar el uso de los bienes comunes, pero al mismo tiempo podían provocar un daño físico a los ciudadanos o a sus inmuebles.

\footnotetext{
53 Murga (1976) pp. 72 y ss.

54 Palermo (1942) p. 38 y ss. En este sentido, Palermo destaca cómo el pretor se valió del importante desarrollo de esta última para ampliar los presupuestos originarios de la novi operis nuntiatio.

55 Branca (1937) pp. 79-81. Este autor advierte, sin embargo, cómo entre los juristas de época clásica tardía no era ya habitual referir la caución a supuestos de pariescommunis.

56 AmunÁtegui (2013) pp. 46-51, especialmente p. 47. Branca (1937) p. 328 y ss. considera que tanto la actio negatoria como la actio ex stipulatu, derivada de la cautio damni infecti, se daban frente a este tipo de actos lesivos provocados por la actuación del fundo vecino. Si bien, la acción negatoria se ejercitaba cuando se trataba de una actividad continuada y la acción estipulatoria cuando tenía carácter puntual. Por otra parte, señala Branca, no existía un criterio general para establecer previamente qué actos eran ilícitos y cuáles estaban dentro que las normas de la convivencia imponía tolerar.
} 


\section{CONCLUSIÓN}

Para preservar el modo de vida que Roma había creado y luego exportado a las provincias, el Derecho Romano desarrolló una serie de medidas con las que, en primer lugar, buscó controlar la demolición incontrolada de edificaciones y limitar la producción de residuos de construcción y demolición. Tal preocupación existió no solo en la Urbe Roma sino también en los municipios y colonias situados en Italia y las provincias. Esto originó la elaboración de una serie de disposiciones al respecto en las que, de forma detallada, se establecieron las limitaciones a las que estaban sometidas las obras de demolición. Las leyes de Tarentum, Urso e Irni recogen una regulación parecida de la cuestión aunque no idéntica. En efecto, cabe observar cómo de una a otra el régimen jurídico se va perfeccionando introduciéndose nuevos matices que permiten mejorarlo. Por otra parte, hay que tener en cuenta que ninguna de estas tres leyes expone las razones por las que se ordenaba tal prohibición. Sin embargo, la lex Iulia municipales, aunque no habla expresamente de la misma, sí explica el porqué de la obligación de mantener en buen estado las fachadas de los inmuebles: el cómodo uso de las vías y espacios públicos. En ellas, pues, no se menciona la cuestión estética, sino que se destaca fundamentalmente la necesidad mantener el entorno urbano en condiciones adecuadas para su uso. Pues, de no ser así, cualquier miembro de la comunidad estaría legitimado para la interposición de una actio popularis, no porque la demolición del edificio le haya provocado un perjuicio patrimonial privado, sino por las consecuencias que para el cuerpo cívico se podían derivar de tales obras. En Roma, la medida más antigua se sitúa en la ley de las XII Tablas; no encontramos otra referencia expresa hasta el siglo I d.C., cuando se publican los senadoconsultos Hosidiano y Volusiano. Este estudio destaca cómo a pesar de ello tal práctico debió haber sido observada también en la Urbe. En este sentido, como ya hemos señalado, la Tabula Heracleensis pone de relieve la importancia del cuidado de las vías, por parte de los propietarios de los inmuebles contiguos, para un adecuado uso de las vías públicas. Y, por otra parte, tampoco se comprendería que juristas y emperadores de época de los Severos se manifestaran abiertamente en defensa de la importancia de la conservación de la belleza estética de la ciudad y, en general, del entorno urbano. Ahora bien, era necesario que estas prohibiciones legales fueran acompañadas de otros instrumentos que hicieran eficaz el mandato contenido en la norma y la denuncia de obra nueva fue el medio utilizado para tal cometido. Se trataba, en este último caso, de un recurso de derecho privado, utilizado para la defensa del interés de la comunidad, lo que pone de relieve la riqueza del intercambio y lo difuso de los límites entre lo público y lo privado. Solo el paso del tiempo consolidará esta separación y pondrá fin a una dinámica con la que, por encima de todo, se pretendía tutelar aquello que era importante para la adecuada convivencia de los ciudadanos.

\section{BIBLIOGRAFÍA CITADA}

Alcázar Avellaneda, Juan Miguel (2010): “Menciones a la licencia urbanística en el Real Decreto 105/2008, de 1 de febrero, por el que se regula la producción y gestión de resi- 
duos de la construcción y demolición”, Práctica urbanística: Revista mensual de urbanismo, vol. XCI: pp. 57-60.

Amunátegui Perelló, Carlos Felipe (2013): "Hacia un concepto de inmisiones en el Derecho chileno", Revista Chilena de Derecho, vol. XL, No 1: pp. 46-86. Disponible en: <http://www.scielo.cl/scielo.php?script=sci_arttext\&pid=S0718$34372013000100003 \& \operatorname{lng}=$ es\&nrm=iso\&tlng=es $>$. Fecha de consulta: 10 septiembre 2015.

Barckhausen, Heinrich (1860): I. Role des interdits dans la procédure romaine, II. De la transcription en Droit francais (Paris).

Betancourt, Fernando (1989): "La construction clandestine: D. 43,24,7,2 (Ulp. 71 ad ed.)", Revue International des Droits de l'Antichitè, 3e. série, vol. XXXVI: pp. 121-130.

Branca, Giuseppe (1937): Damno temuto e damno da cose inanimate nel Diritto romano (Padova, Cedam).

Caballos Rufino, Antonio y Colubí Falcó, José Manuel (2006): "Referentes genéticos de los estatutos municipales hispanorromanos: la Lex municipii Tarentini y la Tabula Heracleensis", en: Rodríguez Neila, Juan Francisco y Melchor Gil, Enrique (eds.), Poder central y autonomía municipal: la proyección pública de las élites romanas de Occidente (Córdoba, Servicio de Publicaciones de la Universidad de Córdoba) pp. 17-54.

Carvajal, Patricio-Ignacio (2013): "Ciudadanía y bien común en la República", Revista Chilena de Derecho, vol. XL, No 1: pp. 373-379. Disponible en: <http:// www.scielo.cl/scielo.php?script=sci_arttext\&pid=S0718-34372013000100017 $\& \operatorname{lng}=e s \& n r m=i s o \& t \operatorname{lng}=e s>$. Fecha de consulta: 22 julio 2015.

Casavola, Franco (1958): Studi sulle azioni popolari romane. Le "actiones populares" (Napoli, Casa Editrice Dott. Eugenio Jovene).

Castro, Rosario (2009): Estipulaciones edictales en el Derecho Romano (Sevilla, Secretariado de Publicaciones de la Universidad de Sevilla).

Crawford, Michael Hewson et al. (1996): Roman Statutes, Tomo I (London, University of London. Institute of Classical Studies).

Domingo, Rafael (1995): "Estudios sobre el primer título del Edicto pretorio, III. Palingenesia y reconstrucción”, Cuadernos Compostelanos de Derecho Romano, vol. VII: pp. 11-133.

D’ Ors, Álvaro (1953): Epigrafía jurídica de la España romana (Madrid, Ministerio de Justicia y Consejo Superior de Investigaciones Científicas).

D’Ors, Álvaro y D’Ors, Xavier (1988): Lex Irnitana: texto bilingüe (Santiago de Compostela, Servicio de Publicaciones e Intercambio Científico da Universidade de Santiago de Compostela).

De Robertis, Francesco M. (1972): La espropiazione per pubblica utilità nel Diritto Romano (Roma, "L'Erma" di Bretschneider, edizione anastatica Milano 1962).

Fernández de Buján, Antonio (1999): "Prólogo", en: Jiménez Salcedo, María del Carmen, El régimen jurídico de las relaciones de vecindad en Derecho Romano (Córdoba, Servicio de Publicaciones de la Universidad de Córdoba) pp. 9-12.

Fernández Fernández, Rosa María (1989): "La ley de la colonia Genetiva Iulia en la experiencia romana sobre las comunidades. Urso 73, 74: de las XII Tablas al Código de Jus- 
tiniano”, en: GONZÁLEZ, Julián (ed.),Estudios sobre Urso. Colonia Iulia Genetiva (Sevilla, Alfar) pp. 79-91.

Galsterer, Helmut (2006): Die römischen Stadtgesetze, en: Capogrossi Colognesi, Luigi Y GabBa, Emilio (coords.), Gli statuti municipali (Pavia. IUSS Press) pp. 31-56.

GANDOLFI, Giuseppe (1955): Contributi allo studio del processo interdittale romano (Milano, Giuffrè).

García SÁnchez, Justo (1975): Teoría de la immissio (Caracteres de las relaciones de vecindad predial en Roma)(Madrid, Departamento de Derecho Romano).

Garnsey, Peter (1976): "Urban Property Investment", en: Finley, Moses, Studies in Roman Property (Cambridge/London/New York/Melbourne, Cambridge University Press) pp. 123-136.

Gelichi, Sauro (2000): "L' eliminazione dei rifiuti nelle città romane del nord Italia tra Antichità ed Alto Medievo", en: Dupré Raventós, Xavier y Remolà Vallerdú, JosepAnton (eds.), Sordes urbis. La eliminación de residuos en la ciudad romana (Roma, "L'Erma" di Bretschneider) pp. 13-23.

Giomaro, Anna Maria (1983): "Ulpiano e le stipulationes praetoriae”, en: Studi in onore di Arnaldo Biscardi, Tomo IV (Milano, Istituto Editoriale Cisalpino La Goliardica).

GLÜCK, Christian Friedrich (1903): Commentario alle Pandette. Tradotto ed arricchito di copiosi note e confronti col còdice civile del Regno d'Italia. Libro XXXIX Parte I. (trad. Pietro Bonfante, Milano, Libraria).

Gómez Buendía,Carmen (2013): “Conservación y estabilidad de los edificios en las fuentes jurídicas clásicas”, en: Fernández de Buján, Antonio (dir.) y Gerez Kraemer, Gabriel M. (coord.), Hacia un Derecho administrativo y fiscal romano, Tomo II (Madrid, Dykinson).

Jiménez SAlCEDo, María del Carmen (1999): El régimen jurídico de las relaciones de vecindad en Derecho Romano (Córdoba, Servicio de Publicaciones de la Universidad de Córdoba).

Karlowa, Otto (1901): Römische Rechtsgeschichte, Tomo II. Privatrecht, Civilprozess, Strafrecht und Strafprozess (Leipzig, Verlag von Veit).

LEWIS, Andrew (1989): "Ne quid in oppido aedificium detegito", en: GonZÁLEZ, Julián (ed.), Estudios sobre Urso. Colonia Iulia Genetiva (Sevilla, Alfar) pp. 41-56.

Liebeschuetz, Wolf (2000): "Rubbish Disposal in Greek and Roman Cities", en: Dupré Raventós, Xavier y Remolà Vallerdú, Josep-Anton (eds.) pp. 51-61.

LuZzatTo, Giuseppe Ignazio (1965): Il problema d'origine del processo extraordinem, Tomo I. Premesse di metodo. I cosidetti rimedi pretori (Bologna, Riccardo Pàtron).

Maffi, Alberto (1977): "Dal sc. Hosidianum al sc. Volusianum: un caso di interpolazione creativa in materia di regolamenti edilizi?", en: Romano, Silvio et al. (eds.), Nozione, Formazione e Interpretazione del Diritto dall' età romana alle esperienze moderne. Ricerche dedicate al profesor Filippo Gallo, Tomo I (Napoli, Jovene Editore) pp. 561-571.

Malavé Osuna, Belén (2011): "Una tendencia novedosa en la investigación romanística: la acción urbanizadora de los romanos y su derecho urbanístico”, en: Fernándezde Buján, Antonio et al. (co-eds.), Hacia un Derecho administrativo y fiscal romano, Tomo I (Madrid, Dykinson) pp. 333-346. 
Masi Doria, Carla (2004): "Droit et nature: inundatio, mutatio alvei et interitus rei. Un caso entre ius Romanorum et tradition du droit romain”, en: Clavel-LêVÊQUe, Monique y Hermon, Ella, Espaces intégrés et ressources naturelles dans l'empire romain (Quebec, Presses universitaries de Framche-Comté) pp. 201-218.

Melchor Gil, Enrique (2010): "Sobre Digesto L, 10,3, pr. y la necesidad de solicitar permiso al emperador para financiar la construcción de edificios de espectáculos", Mélanges de l'Ecole francais de Rome. Antiquité, vol. CXXII, No 1: pp. 37-42.

Mozzillo, Attanasio (1960): Contributi allo Studio dell'stipulationes praetoriae (Napoli, Publicazioni della Facoltà Giuridica dell' Università di Napoli).

Murga Gener, José Luis (1976): Protección a la estética en la legislación urbanistica del alto imperio (Sevilla, Secretariado de Publicaciones de la Universidad de Sevilla).

Murga Gener, José Luis (1986): El edificio como unidad en la jurisprudencia romana y en la lex (Sevilla, Secretariado de Publicaciones de la Universidad de Sevilla).

Palermo, Antonio (1942): Il procedimento cauzionale nel Diritto romano (Milano, Giuffrè).

PARICIO, Javier (1982): "Algunas notas sobre la cautio damni infecti”, en: Studi in onore di Cesare Sanfilippo, Tomo II (Milano, Giuffrê).

Pérez Zurita, Antonio David (2011): La edilidad y las élites locales en la Hispania romana. La proyección de una magistratura de Roma a la administración municipal (Córdoba/Sevilla, Servicio de Publicaciones de la Universidad de Córdoba y Secretariado de Publicaciones de la Universidad de Sevilla).

Ponte, Vanessa (2007): Régimen jurídico de las vías públicas en Derecho Romano (Madrid, Dykinson).

Procchi, Federico (2001): "Si quis negotiandi causa emisset quod aedificium...prime considerazioni su intenti negoziali e <<speculazione edilizia >> nel Principato", Labeo, vol. XLVII, No 1: pp. 411-438.

RaINER, J. Michael (1987): "Zum senatusconsultum Hosidianum”, Tidjschrift voor Rechtsgeschiedenis vol. LV: pp. 31-38.

Riccobono, Salvatore (1941): Fontes iuris Romani anjustinianei, Tomo I (Firenze, Barbèra).

Robinson, Olivia (1996): Ancient Rome. City Planning and Administration (London, Routledge).

Robles, Juan Ramón (2001): “De la protección de los edificios privados. Estudio comparado de los textos municipales hispanos del siglo I, el Código de Justiniano y la siete Partidas", Anales de Derecho. Universidad de Murcia, vol. XIX: pp. 181-193.

Rodger, Alan (1972): Owners and Neighbours in Roman Law (Oxford, Clarendon Press).

Rodríguez GonzÁlez (2006): "La manutenzione delle strade di Roma. Un procedimento specifico nell Tavola di Heraclea", en: Capogrossi Colognesi, Luigi y Gabba, Emilio (coords.), Gli statuti municipali (Pavia. IUSS Press) pp. 397-410.

Rodríguez López, Rosalía (2011): "La licencia urbanística y el derecho de sobreedificación (CTh. 15,1,50)", en: Fernández de Buján, Antonio et al. (co-eds.), Hacia un Derecho administrativo y fiscal romano (Madrid, Dykinson) pp. 393-408.

Rodríguez NeIla, Juan Francisco (2011): "Problemas medioambientales urbanos en el mundo romano”, en: Remolà Vallverdú, Josep-Anton y Acero Pérez, Jesús (eds.), La 
De CASTRO-CAmERo, Rosario $\square$ Medidas para prevenir la producción de escombros...

gestión de los recursos urbanos en Hispania. Xavier Dupré Raventós (1956-2006) Inmemoriam (Mérida, Consejo Superior de Investigaciones Científicas) pp. 27-52.

Ruiz, Salvador y Alburquerque, Juan Manuel (2011): "Algunas notas referentes a la experiencia administrativa romana de protección de los recursos naturales, en: FERNÁNDEZ de BujÁn, Antonio et at. (co-eds.), Hacia un Derecho administrativo y fiscal romano, Tomo I (Madrid, Dykinson) pp. 409-426.

SantuCCI, Gianni (2001): Operis novi nuntiatio iuris publici tuendi gratia (Padova, Cedam).

Terrazas Ponce, Juan David (2010): "El concepto de res publica, I. La noción de res en el lenguaje de los juristas romanos", Revista de Estudios Histórico-Jurídicos, vol. XXXII: pp. 127-158.

Zamora ManZano, José Luis (2005): "El ilícito penal medioambiental en Roma: la contaminación y degradación de las aguas en el espacio urbano y rural”, en: CALZADA GonZÁlez, Aránzazu y Camacho de los Ríos, Fermín (Coords.), El Derecho penal: de Roma al Derecho actual (Madrid, Edisofer) pp. 675-707.

Zoz, Maria Gabriella (1999): Riflessioni in tema di res publica (Torino, Giappichelli). 